Résumés des conférences et travaux

\title{
Archives orales et histoire des organisations
}

\section{Florence Descamps}

\section{(2) OpenEdition \\ 1 Journals}

Édition électronique

URL : https://journals.openedition.org/ashp/1975

DOI : 10.4000/ashp. 1975

ISSN : 1969-6310

Éditeur

Publications de l'École Pratique des Hautes Études

\section{Édition imprimée}

Date de publication : 1 septembre 2017

Pagination : 261-262

ISSN : 0766-0677

\section{Référence électronique}

Florence Descamps, "Archives orales et histoire des organisations", Annuaire de l'École pratique des hautes études (EPHE), Section des sciences historiques et philologiques [En ligne], 148 | 2017, mis en ligne le 28 septembre 2017, consulté le 06 juillet 2021. URL : http://journals.openedition.org/ashp/1975 ; DOI : https://doi.org/10.4000/ashp.1975 


\title{
ARCHIVES ORALES ET HISTOIRE DES ORGANISATIONS
}

\author{
Maître de conférences : $\mathrm{M}^{\text {me }}$ Florence DescAmps
}

Programme de l'année 2014-2015 : I. Des archives sonores à la mémoire orale : la «fabrique » d'un patrimoine culturel immatériel? (premier semestre). - II. CRCT (second semestre).

\section{Des archives sonores à la mémoire orale : la «fabrique » d'un patrimoine culturel immatériel?}

L'articulation qui peut exister entre oralité, histoire, mémoire et patrimoine a dès l'entre-deux-guerres fait en France l'objet de questionnements de la part des sciences sociales; elle a donné lieu à des pratiques d'enquête, appuyées sur l'innovation technologique en matière de prise de son et d'images. Le premier axe d'étude consiste à établir la généalogie et l'histoire de ces pratiques, depuis les premières fixations conservatoires et scientifiques de la parole dès le tournant $\mathrm{du} \mathrm{xx}^{\mathrm{e}}$ siècle jusqu'aux actuelles enquêtes de mémoire orale filmées et à étudier les configurations scientifiques, techniques et sociales qui permettent leur émergence (archives de la parole, traditions orales, ethnographie et ethnomusicologie, histoire orale, archives orales, témoignages oraux, enquêtes orales, corpus oraux, mémoire orale, histoire visuelle, etc.)

Le deuxième axe consiste à étudier comment ces pratiques d'enquête se sont doublées (ou non) de pratiques de patrimonialisation. Depuis les Archives de la Parole créées en 1911 au sein de la Sorbonne jusqu'à la notion de " patrimoine culturel immatériel », élaborée puis imposée par l'UNESCO en 2003, le séminaire s'interroge sur la manière dont la parole enregistrée et la mémoire mise en parole se trouvent elles aussi prises dans la « fabrique » du patrimoine. Comment analyser la demande sociale en matière de mémoire? En quels termes et par quels canaux s'exprime-t-elle? Quels acteurs se saisissent actuellement de cette demande sociale et cherchent à y répondre? Quels sont les indices qui permettent de parler de patrimonialisation de la parole et de la mémoire? Peut-on parler de régimes de mémorialité comme on parle de régimes d'historicité (F. Hartog)? A quelles conditions peut-on parler de la constitution d'un patrimoine oral ou d'un patrimoine mémoriel?

Le troisième axe vise à analyser les effets de l'adjonction de l'image animée à la production du récit autobiographique à travers l'entretien. Pourquoi filmer les entretiens? Quels dispositifs filmiques adopter et quels en sont leurs effets? Comment analyser et valoriser les images produites? Quels sont les apports comparés de l'image et du son? L'image accélère-t-elle ou modifie-elle le processus de patrimonialisation? L'histoire orale est-elle appelée à devenir une histoire visuelle?

Le quatrième axe de travail est pratique et méthodologique; il s'inscrit délibérément dans une démarche d'ingénierie patrimoniale et souhaite offrir les outils méthodologiques, scientifiques, juridiques et éthiques nécessaires pour répondre à 
la demande en matière de mémoire et de patrimoine oral. La question juridique et éthique fait désormais l'objet d'une séance entière.

Pour appuyer cette réflexion, plusieurs études de cas ont été présentées au cours du séminaire.

Une séance a été consacrée aux collectes d'archives orales sur l'histoire portuaire et sur l'histoire du transport des marchandises, notamment la conteneurisation qui a révolutionné la marine marchande, les échanges commerciaux et les métiers portuaires. Laure Bouscasse a présenté le résultat de ses travaux, de la collecte jusqu'à la valorisation de ces archives orales, soit dans un cadre muséographique soit dans une exposition. Cette présentation a fait l'objet d'un article « Sonorités maritimes et portuaires » dans le Bulletin de l'Association des archives sonores, orales et audiovisuelles, $\mathrm{n}^{\circ} 41,2015$. Consultable en ligne https://afas.revues.org/2952.

\section{II. $C R C T$}

Le second semestre a été consacré, d'une part à la rédaction d'un projet éditorial en vue de la publication du mémoire inédit de mon dossier d'habilitation à diriger des recherches (Le ministère des Finances, la réforme administrative et la modernisation de l'Etat 1914-1974) et d'autre part, au développement de deux nouveaux axes de recherche, amorcés en 2015 :

- L'impact de la Grande Guerre sur l'État en France, et plus spécifiquement sur le système de gestion des finances publiques;

— Les figures du pouvoir administratif à travers les arts, et plus particulièrement à travers l'architecture administrative. Avec une étude de cas portant sur la construction du nouveau ministère des Finances à Bercy (processus décisionnel, concours d'architecture, construction, symbolique du pouvoir). Ces travaux prennent place dans le cadre de la nouvelle équipe Histara de l'EPHE (Histoire de l'art et histoire de l'administration).

Ces deux chantiers de recherche seront poursuivis dans les mois prochains. 